\title{
(RE)PENSANDO O CONCEITO DE TRADUÇÃO INDIRETA EM OBRAS LITERÁRIAS
}

\author{
Vanessa Lopes Lourenço Hanes ${ }^{1 \times}$ \\ ${ }^{1}$ Universidade Federal Fluminense, Niterói, Rio de Janeiro, Brasil
}

\section{Resumo}

Apesar da recente expansão e consolidação dos Estudos da Tradução enquanto campo do saber, há ainda poucos estudos nesta área voltados à tradução indireta. Considerando esta lacuna, o presente texto aborda o conceito de tradução indireta tomando como base três contextos tradutórios diferentes, e objetiva refletir sobre a noção tradicional do que pode ser considerado uma tradução literária indireta, visando expandi-la. Palavras chave: Tradução Indireta; Tradução Literária; Teoria da Tradução.

\section{(RE)THINKING THE CONCEPT OF INDIRECT TRANSLATION IN LITERATURE}

\begin{abstract}
In spite of the recent expansion and consolidation of Translation Studies as a scholarly field, there are few studies in this area concerned with indirect translation. Considering this gap, this text deals with the concept of indirect translation in three different translational contexts, aiming to reflect on and expand the traditional understanding of what may be considered an indirect literary translation.

Keywords: Indirect Translation; Literary Translation; Translation Theory.
\end{abstract}

\footnotetext{
Professora adjunta de língua inglesa na Universidade Federal Fluminense (UFF). Mestre em Estudos da Tradução (2011) e Doutora em Estudos da Tradução (2015) pela Universidade Federal de Santa Catarina. Suas pesquisas atualmente englobam: variações e registros da língua inglesa e suas traduções para o português brasileiro; traduções da literatura de massa anglófona no Brasil; e abordagens da oralidade em traduções brasileiras para diferentes mídias. Seu e-mail é: vanessahanes@id.uff.br. ORCID: https://orcid.org/0000-00020413-0190.
} 
O presente artigo parte da premissa de que a tradução indireta hoje pode, sob algumas perspectivas, ser considerada um dos calcanhares de Aquiles dos Estudos da Tradução no Brasil e no mundo. Li (2017, p. 181) afirma que "apesar de a tradução indireta ter sempre sido comumente aceita e necessária, ela raramente é discutida nos estudos da tradução". ${ }^{1}$ Não seria talvez acertado classificar a tradução indireta como sempre comumente aceita, uma vez que ela atualmente tende a gozar de baixo prestígio em diversos contextos, mas o seu relevante papel histórico e a sua paradoxal posição marginalizada na academia não podem ser contestados. Pieta (2012) é uma das poucas pesquisadoras da área que se propôs a discorrer sobre a tradução indireta de maneira mais abrangente, destacando a posição ainda periférica ocupada atualmente por ela enquanto objeto de estudo, apesar de tímidas iniciativas de exploração da temática já serem identificadas. Ela afirma haver inclusive a ausência de uma nomenclatura universalmente aceita para se referir a tais tipos de tradução. E mesmo o lugar da tradução indireta enquanto subárea de pesquisa no universo acadêmico dos Estudos da Tradução está longe de ser claro: Koskinen e Paloposki (2010) indicam que a tradução indireta é, por exemplo, discutida por vezes no âmbito da retradução, como se fosse direta e necessariamente atrelada a ela, o que percebem como negativo.

Em meio a tantas incertezas, parece oportuno dar margem a alguns questionamentos que têm relação não só com o lugar da tradução indireta na academia, mas também referentes à própria essência e conceitualização do termo, começando por pensar: afinal de contas, o que é uma tradução indireta? A definição tradicionalmente aceita é que as traduções indiretas são "traduções produzidas com base em outra tradução" (SCHÄFFNER, 2010, p. 238). ${ }^{2}$ Mas será que é possível ir um pouco além desse entendimento óbvio e necessário do conceito de indireto, utilizando-o como ponto de partida, mas não como limite, para descrever e melhor compreender determinados fenômenos tradutórios reais? A intenção aqui é investigar a possibilidade de uma resposta positiva a tal questionamento.

Assim sendo, o objetivo deste texto é explorar o conceito tradicional de tradução indireta e, com base em três exemplos isolados, pensar sobre a possível flexibilização do que poderia ser classificado sob tal rótulo, não necessariamente chegando a conclusões definitivas, mas problematizando um conceito quase que onipresente quando se pensa na história da prática da tradução em diferentes nações e, entretanto, ainda carente de maior reflexão. A seguir serão apresentados os três exemplos selecionados para ilustração do debate proposto.

\section{O caso da tradução pseudo-indireta de um nome próprio}

O primeiro caso a ser analisado aqui já foi abordado anteriormente em Hanes (2015), mas nunca em um contexto que enfocasse especificamente a tradução indireta: trata-se daquilo que aqui será chamado de tradução pseudo-indireta. O exemplo em questão foi retirado de uma tradução brasileira realizada em 1933 por Heitor Berutti do livro The Murder of Roger Ackroyd, de Agatha Christie, e publicada pela Livraria do Globo. O que chama a atenção com relação à temática debatida no 
presente artigo é que o primeiro nome do narrador e também um dos principais personagens daquela história, o Dr. James Sheppard, é traduzido como Jaques, e não como Tiago, que seria a tradução mais usual para o referido nome. E algo à primeira vista tão simples abre portas para questionamentos diversos. Obviamente o nome Jaques é uma versão abrasileirada do nome francês Jacques. Mas por que Berutti optaria por usar este nome na tradução de uma obra de origem anglófona?

Amorim (2000) traz à luz aspectos que poderiam talvez justificar tal escolha. Segundo ela, no começo do século XX, os livros comercializados no Brasil eram importados principalmente da França, e o francês prevalecia como lingua franca literária da nação, sendo utilizado como intermediário para a tradução. Traduções feitas de originais em língua inglesa ainda eram, até certo ponto, uma novidade. E a cultura francesa como um todo era ainda vista no Brasil como sinônimo de requinte e civilização. Levando-se em conta que Berutti cresceu nessa atmosfera literária de valorização da língua e cultura francesas, esse cenário poderia por si só explicar a sua opção tradutória.

Entretanto, a possibilidade de se tratar, de fato, de uma tradução indireta via língua francesa na qual o nome Jacques aparece não poderia ser descartada. Assim, uma versão francesa da mesma obra lançada em 1927 pela editora Librairie des Champs-Élysées, aparentemente a primeira a publicar livros de Christie em francês, foi consultada. Porém, descobriu-se que, nesse caso, o nome do personagem aparece do mesmo modo como no original em língua inglesa: James. Assim, a possibilidade de Berutti haver usado o nome Jaques por conta de uma tradução indireta convencional é bastante remota. Por outro lado, a possibilidade de tal escolha ser realmente uma tentativa de sofisticação do texto de Christie para o público brasileiro, através de um "afrancesamento", parece plausível. É daí que surge a ideia de classificar a tradução do nome adotada por Berutti como pseudo-indireta. Uma tradução pseudo-indireta indicaria, portanto, um texto que dá a falsa impressão de haver sido traduzido através de um texto intermediário, neste caso de um país prestigiado pelo leitorado alvo. Tal concepção acaba por expandir os conceitos de tradução indireta e de pseudotradução, ${ }^{3}$ ao combiná-los para explicar um fenômeno observado em uma tradução real.

\section{O caso da tradução indireta de Beowulf no Brasil}

O segundo caso a ser considerado aqui é o da tradução brasileira feita a partir de uma tradução da obra Beowulf realizada pelo aclamado autor britânico J. R. R.Tolkien, do anglo-saxão para a língua inglesa. A tradução para o português é de Ronald Eduard Kyrmse e foi publicada no Brasil em 2014 pela editora Martins Fontes.

John Ronald Reuel Tolkien (1892-1973) foi um ilustre acadêmico da Universidade de Oxford, mas se tornou conhecido mundialmente em grande parte por suas obras de ficção que foram publicadas no Brasil sob os títulos $O$ Hobbit e O Senhor dos Anéis. Seus livros foram traduzidos para mais de 30 idiomas e venderam mais de 50 milhões de exemplares no mundo todo, além de terem se tornado obras fílmicas altamente aclamadas por público e crítica. O que é menos 
divulgado entre as massas é que, além de ser muito traduzido, Tolkien também se interessava pela prática tradutória e era grande estudioso do medievalismo. A combinação desses interesses resultou em uma tradução do poema épico anglosaxão Beowulf, escrito entre 700 e 750 d. C. A tradução de Tolkien foi concluída em 1926, porém demorou décadas para ser publicada.

O que é interessante neste caso de tradução indireta é que, embora no Brasil já existam traduções anteriores do poema épico em questão, como a tradução em verso feita por Erick Ramalho e cuja segunda edição foi publicada pela editora Tessitura em 2011, a publicação da tradução realizada por Tolkien ocorre na realidade devido à fama do tradutor que excede, em muito, a do poema em si entre o leitorado brasileiro. Assim, o livro foi traduzido e comercializado como um livro em grande parte da autoria de é Tolkien: são os seus paratextos relacionados à tradução de Tolkien que o validaram enquanto objeto de uma tradução indireta. O prefácio e a introdução da tradução, ambos de autoria do filho de Tolkien, bem como os ricos comentários daquele autor sobre o seu trabalho tradutório, foram os motivos para que o texto indireto, traduzido em prosa e apresentado em edição bilíngue, fosse trazido ao público brasileiro. Em uma crítica de autoria de Reinaldo José Lopes e publicada no jornal Folha de São Paulo, por exemplo, lê-se o seguinte título: “Tradução de 'Beowulf' revela maestria narrativa de Tolkien”.

Não há, até onde foi possível encontrar, estudos que atrelem a opção pela tradução indireta à figura de uma celebridade como Tolkien. É inegável que o que ocorre aqui é mais do que caberia no conceito estrito de uma tradução indireta: o que se dá é uma redistribuição de autoria, uma vez que o autor do texto original, neste caso desconhecido, fica em segundo plano, e mesmo o texto original passa a ser de importância secundária para que o tradutor ocupe um lugar de proeminência na comercialização da obra traduzida, destoando da posição de invisibilidade tradicionalmente atribuída ao profissional de tradução conforme advogado por Venuti (1995).

\section{O caso de tradução indireta entre um livro e uma graphic novel}

Por fim, será apresentado o terceiro caso que ilustra outro tipo inusitado de tradução indireta: o da tradução de uma graphic novel adaptada para o francês a partir de uma obra literária escrita originalmente em língua inglesa, a qual foi depois traduzida de volta para a língua inglesa no formato de graphic novel.

A graphic novel, também conhecida no Brasil como romance gráfico, é uma história produzida em quadrinhos, mas que se diferencia do que é tradicionalmente conhecido como histórias em quadrinhos, os populares gibis voltados majoritariamente ao público infantil, por ser um termo utilizado para designar histórias mais longas e elaboradas, com maior nível de densidade e complexidade, semelhantes às obras literárias em prosa, e concebidas para um público adulto. Há diversas graphic novels comercializadas atualmente que foram adaptadas a partir de obras literárias canonizadas ou não canonizadas, conforme aquela ao redor da qual se centra o caso aqui apresentado. 
A obra literária em questão também é de autoria de Agatha Christie, cuja literatura detetivesca foi o objeto principal de pesquisa da tese de doutorado da autora do presente artigo: trata-se de Ten Little Niggers, livro publicado pela primeira vez no Reino Unido em 1939 pela editora William Collins. A história se desenrola ao redor de uma rima infantil do começo do século XX, na qual os personagens, dez negrinhos, vão morrendo um a um.

Em 2002 esta obra literária de Christie foi adaptada para o público francês por François Rivière e pelo ilustrador Frank Leclercq, em uma graphic novel intitulada Dix Petits Nègres. ${ }^{4}$ E é a partir daí que o caso de tradução indireta em tela se desenrola: no ano de 2009 a graphic novel francesa foi trazida ao público norte-americano pela editora Harper Collins, através de uma tradução do texto adaptado em francês por Rivière. O título utilizado nos Estados Unidos, porém, foi And Then There Were None, o mesmo adotado para as traduções literárias daquela obra desde a sua primeira edição em solo norte-americano. ${ }^{5}$

O questionamento que se coloca aqui é como descrever e/ou classificar esta situação tradutória na qual:i) em primeirolugar, uma tradução concomitantemente interlingual e intersemiótica é feita da obra de Christie para o francês, passando o seu texto não só do inglês para o francês e adaptando-o com cortes severos na extensão do enredo, mas indo além, passando também do formato de livro para o de quadrinhos ilustrados; e ii) em segundo lugar, o texto é trazido de volta ao público anglófono nesse novo formato, usando a graphic novel francesa como base para a apresentação do texto ilustrado ao público anglo-americano?

Está-se aqui diante de uma tradução que se dá de forma indireta graças ao meio de transmissão textual. Ou seja: embora o texto de Christie tenha sido originalmente escrito em língua inglesa no formato de um livro tradicional, ele foi devolvido indiretamente ao público anglófono em um novo formato, o de graphic novel, o qual passa pela língua francesa. Embora a tradução da obra francesa tenha se acomodado às expectativas do público de língua inglesa, por exemplo com a exclusão do termo nigger no título e no conteúdo das páginas internas, ocorre aqui uma espécie de transferência indireta do texto, uma vez que a história da graphic novel ainda traz elementos diretamente derivados da adaptação francesa.

Reflexões sobre os casos apresentados: afinal, o que determina uma tradução indireta?

Parece importante indicar que se entende claramente não ser possível chegar a conclusões definitivas sobre um fenômeno tradutório como um todo com uma amostra tão pequena como aquela aqui considerada, composta de três casos isolados advindos de contextos tão diferentes entre si com relação, por exemplo, à posição ocupada pelas obras literárias analisadas (indo desde uma obra canonizada como Beowulf até as obras de literatura policial de massa de Christie) e aos períodos históricos em que cada obra traduzida se situa (desde a década de 
1930 até os anos 2000). Por outro lado, os breves achados descritos aqui abrem portas para questionar: o conceito de tradução indireta conforme aprendido e reproduzido na academia consegue abarcar os fenômenos descritos nos casos mencionados? Dizer simplesmente que se trata de uma tradução produzida com base em outra é suficiente para explicar os casos apresentados acima?

A resposta provavelmente seria sim e não. No caso de Beowulf, trata-se realmente de uma tradução indireta no sentido mais estrito do termo, já que o livro brasileiro adveio de um intermediário. Mas o problema é que não se trata só disso, uma vez que essa tradução indireta não existiria se não fossem os seus paratextos, pois são eles que determinam a sua vendabilidade em um mercado que, caso contrário, já estaria servido pela tradução anterior sob uma ótica estritamente literária. Esta situação pede o entendimento da tradução indireta atrelada a um contexto mercadológico que, surpreendentemente, ainda hoje encontra amplos filões interessados em traduções indiretas desde que as mesmas sejam atestadas por um nome como o de J. R. R. Tolkien, uma espécie de "selo de qualidade" editorial.

Já com relação ao que ocorre na tradução de Berutti, o conceito de tradução indireta falharia mesmo para uma compreensão inicial do fenômeno, uma vez que não existe aparentemente nenhum texto intermediário. Mas há, por outro lado, um intermediário muito maior: o sistema cultural francês, ainda visto como filtro desejável para as publicações literárias no Brasil (supostamente) póscolonial de 1933. O simples uso de um nome poderia servir de incentivo para pensar debates mais amplos associando a tradução indireta e a pseudotradução a questões pós-coloniais na história brasileira mais recente, combinando estes e outros conceitos para o melhor entendimento do que se dá na prática tradutória.

Tanto no caso da tradução indireta do canonizado Beowulf quanto da literatura de massa de Christie feita por Berutti, percebe-se um atrelamento entre o conceito de tradução indireta e o prestígio da obra traduzida, seja na pessoa do tradutor em si, como no caso de Tolkien, ou da suposta nação de origem, como no caso da França. A hipótese de uma associação entre textos indiretos publicados recentemente e o grau de prestígio que poderia servir como motivação para a sua existência potencialmente resultaria em uma investigação bastante interessante.

Por fim, o caso da graphic novel leva a pensar se o indireto na tradução também poderia ser estendido às traduções intersemióticas: neste caso, o texto escrito passa a ser uma combinação de escrito e ilustrado. É verdadeiro que, uma vez que a graphic novel veio do francês para o inglês, ela poderia ser chamada de indireta segundo o entendimento tradicional do termo. Mas o fato de a versão francesa ser uma adaptação do clássico detetivesco inglês acaba por criar uma situação única em que o texto foi traduzido indiretamente não só do francês para o inglês, mas do inglês para o inglês através de uma outra mídia em francês. $\mathrm{O}$ indireto, portanto, é intralingual, mas é também interlingual, o que, mais uma vez, expande o entendimento tradicional de uma tradução indireta.

Estas breves reflexões servem para demonstrar que há muito a ser descoberto, e expandido, com relação ao entendimento atual de traduções 
indiretas. Traduções indiretas não são somente coisas de um passado remoto, utilizadas como única opção em momentos de acesso linguístico limitado, mas podem ser fenômenos tradutórios atuais, presentes no mundo globalizado, frutos de motivações mais complexas do que a falta de acesso à língua do texto original, e merecedores de estudos sistemáticos.

\section{Considerações finais}

Os três exemplos apresentados no presente texto não são frutos de uma busca sistematizada, mas sim de achados inesperados resultantes de outras pesquisas nas quais a tradução indireta não ocupava posição central. O fato de estas descobertas terem se dado de maneira quase que acidental serve para demonstrar que os casos debatidos só representam a ponta de um iceberg com relação às possibilidades de expansão das pesquisas e reflexões sobre a tradução indireta, tema ainda marginalizado em pesquisas acadêmicas no Brasil e no mundo. Estudos futuros, organizados de forma mais sistemática e ampla, provavelmente trarão à luz exemplos novos e mais contundentes para a demonstração não só da possibilidade, mas da necessidade de reconsideração do modo como as traduções indiretas são compreendidas e classificadas.

Notas

1. "although indirect translation has always been commonly accepted and necessary, it is seldom discussed in translation studies".

2. "translations produced on the basis of another translation". Contrariamente ao que possa parecer, é possível ainda encontrar no Brasil traduções comercializadas recentemente que foram realizadas obedecendo a esta definição mais tradicional de "indireta": um caso seria a tradução da obra originalmente escrita em sueco e intitulada Män som hatar kvinnor (literalmente Homens que odeiam mulheres), de Stieg Larsson (1954-2004), publicada originalmente pela editora Norstedts Förlag em 2005. A tradução brasileira, realizada indiretamente por Paulo Neves através de uma tradução francesa da obra lançada em 2006, foi publicada em 2008 pela Companhia das Letras sob o título Os homens que não amavam as mulheres, concomitantemente com aquelas comercializadas em vários outros países, incluindo Portugal e os Estados Unidos.

3. Robinson (2005, p. 183) define pseudotradução do seguinte modo: "A pseudotranslation might be defined as a work whose status as 'original' or 'derivative' is, for whatever social or textual reason, problematic".

4. A graphic novel francesa foi também publicada no Brasil no ano de 2010, traduzida por Alexandre Boide para a editora L\&PM sob o título O Caso dos Dez Negrinhos.

5. Apesar de esta obra literária de Christie ter sido por décadas publicada em solo britânico sob o título Ten Little Niggers, o título do mesmo livro nos Estados Unidos sempre foi And Then There Were None, devido às reverberações altamente racistas da utilização do termo nigger no contexto norte-americano. O livro, portanto, passou por mudanças não só em seu título, mas em seu conteúdo interno para que todas as instâncias deste termo visto como tabu fossem eliminadas. Por si só, tais circunstâncias trazem à tona um debate potencialmente frutífero: as edições norteamericanas poderiam ser classificadas como traduções intralinguais das obras de Christie? Mais detalhes sobre esta questão podem ser encontrados em Hanes (2018). 


\section{Referências}

AMORIM, S. M. de. Em busca de um tempo perdido: edição de literatura traduzida pela editora Globo (1930-1950). São Paulo: EDUSP, 2000.

CHRISTIE, A. O assassinato de Roger Acrkoyd. Tradução de Heitor Berutti. Porto Alegre: Livraria do Globo, 1933.

CHRISTIE, A. And then there were none. Adaptação de François Rivière. Tradução de David Brawn. London: Harper Collins, 2009.

CHRISTIE, A. Dix petits nègres. Adaptação de François Rivière. Brussels: Claude Lefrancq Editeur, 2002.

CHRISTIE, A. O caso dos dez negrinhos. Adaptação de François Rivière. Tradução de Alexandre Boide. Porto Alegre: L\&PM, 2010.

HANES, V. L. L. The language of translation in Brazil: written representations of oral discourse in Agatha Christie. 2015. 308 f. Tese (Doutorado em Estudos da Tradução) - Programa de Pós-Graduação em Estudos da Tradução, Universidade Federal de Santa Catarina, Florianópolis, 2015. Disponível em: <https:// repositorio.ufsc.br/handle/123456789/158404?show=full $>$. Acesso em: 30 maio 2018.

HANES, V. L. L. The retitling of Agatha Christie's Ten Little Niggers in Anglophone and Lusophone markets. Translation and Literature, v. 27, n. 2, p. 184-194, 2018.

LARSSON, S. Os homens que não amavam as mulheres. Tradução de Paulo Neves. São Paulo: Companhia das Letras, 2008.

LI, W. The complexity of indirect translation. Orbis Litterarum, v. 72, n. 3, p. 181-208, 2017.

LOPES, J. R. Tradução de 'Beowulf' revela maestria narrativa de Tolkien. Folha de São Paulo, 14 jun.2014. Disponível em: <https://www1.folha.uol.com.br/ ilustrada/2014/06/1470039-critica-traducao-de-beowulf-revela-maestrianarrativa-de-tolkien.shtml>. Acesso em: 29 set. 2018.

KOSKINEN, K.; PALOPOSKI, O. Retranslation. In: DOORSLAER, L. v.; GAMBIER, Y. (Ed.). Handbook of translation studies. Amsterdam: Benjamins, 2010. v. 1, p. 294-298.

PIETA, H. Patterns in (in) directness: An exploratory case study in the external history of Portuguese translations of Polish literature (1855-2010). Target. International Journal of Translation Studies, v. 24, n. 2, p. 310-337, 2012.

ROBINSON, D. Pseudotranslation. In: BAKER, M. (Ed.). Routledge encyclopedia of translation studies. London: Routledge, 2005, p. 183- 185.

SCHÄFFNER, C. Norms in Translation. In: DOORSLAER, L. v.; GAMBIER, Y. (Ed.). Handbook of translation studies. Amsterdam: Benjamins, 2010. v. 1, p. 235-244.

TOLKIEN, J. R. R. Beowulf: uma tradução comentada. Tradução de Ronald Eduard Kyrmse. Rio de Janeiro: WMF Martins Fontes, 2014.

VENUTI, L. The translator's invisibility: a history of translation. New York: Routledge, 1995.

Recebido em: 30/09/2018

Aceito em: 05/02/2019 